\title{
A EXPERIÊNCIA DE LAZER DE ESTUDANTES DO CURSO DE LICENCIATURA EM EDUCAÇÃO FÍSICA DE UMA INSTITUIÇÃO DE ENSINO SUPERIOR DO DISTRITO FEDERAL
}

\author{
Ioranny Raquel Sousa \\ Universidade Católica de Brasília, Brasília, Distrito Federal, Brasil \\ Rafaello Pinheiro Mazzoccante \\ Universidade Católica de Brasília, Brasília, Distrito Federal, Brasil \\ Gislane Ferreira de Melo \\ Universidade Católica de Brasília, Brasília, Distrito Federal, Brasil \\ Junior Vagner Silva \\ Universidade Católica de Brasília, Brasília, Distrito Federal, Brasil \\ Tânia Vieira Sampaio \\ Universidade Católica de Brasília, Brasília, Distrito Federal, Brasil
}

\section{Resumo}

O lazer pode ser compreendido por dois aspectos constituintes: a atitude e o tempo. Sendo assim, o objetivo do presente estudo foi investigar a compreensão e a vivência do lazer na vida de futuros profissionais da área da Educação Física. A amostra foi composta por 175 estudantes do curso de Licenciatura em Educação Física de uma Instituição de Ensino Superior do Distrito Federal. Os resultados indicam que estes estudantes dedicam algum tempo ao lazer, mas pode-se concluir que possuem pouca experiência com equipamentos de lazer. As principais barreiras para utilização dos equipamentos são a falta de tempo, a falta de interesse e a localização dos equipamentos.

Palavras-chave: Lazer. Interesses Culturais. Equipamentos.

\section{Introdução}

O lazer começou a ter sua relevância na vida em sociedade depois da Revolução Industrial. A essa época, os trabalhadores eram submetidos a fatigantes horas de trabalho, e tiveram início as manifestações contrárias às duras cargas horárias, o que gerou uma consciência sobre a necessidade de tempo livre que propiciasse o desenvolvimento de outras capacidades alheias ao trabalho. Isso resultou no equilíbrio entre trabalho e lazer (QUEIROZ e SOUSA, 2009). 
Na concepção de Marcellino (2002), o lazer é definido como qualquer atividade realizada após as obrigações trabalhistas, familiares, sociais e religiosas, podendo ser compreendido por dois aspectos que o constituem: a Atitude, que valoriza a disponibilidade pessoal para desfrutar do prazer decorrente da realização de certa atividade; e o Tempo, no qual se considera como prática de lazer o momento dedicado a atividades desenvolvidas no período disponível das muitas obrigações.

Segundo Marcellino (2002), o lazer marcado por uma visão funcionalista tende somente ao aqui e agora. Por isso, o autor faz séria crítica a esta perspectiva, na medida em que isto desqualifica o lazer, atrelando-o a uma visão utilitarista. Nesse caso, este serviria apenas para recuperar a força de trabalho, como um meio compensatório e de forma hedonística.

Apesar de o lazer poder ser considerado como um meio de divertimento e descanso, Marcellino (2003) acredita que o mesmo não possa servir simplesmente como um atenuador de tensões ou como algo que ajuda na convivência com as injustiças sociais. Ao contrário, o lazer pode ser visto com uma perspectiva crítica e criativa, na qual é tido como direito de fruição e não apenas mérito pelo trabalho realizado, possibilitando mudanças sociais a longo prazo e de maneira subjetiva, e promovendo processos de emancipação e empoderamento das pessoas (SAMPAIO, 2004; SAMPAIO, 2008).

Apresentando diferenciações de acordo com as áreas, ou seja, de acordo com interesses culturais distintos, as experiências no lazer podem ser realizadas pela motivação do indivíduo em praticar, conhecer ou contemplar-se com atividades: Físicas-esportivas (caracterizado pelo envolvimento com esportes e exercícios físicos, bem como pelo contato com várias outras atividades relacionadas às manifestações da Cultura Corporal do Movimento, como ginásticas, danças, lutas, jogos motores, dentre outras); Manuais (manipulação ou transformação de objetos, como artesanatos em geral, bricolagem e jardinagem); Artísticas (atividades que envolvem o contato com o fictício, faz-de-conta, ou seja, com o mundo irreal, estando relacionadas às artes plásticas, musicais, dramatização, etc); Intelectuais (com o mundo real, informações e intelecto); Sociais (manutenção ou ampliação do círculo de amizades); Turísticas (atividades voltadas para a experiência com novas paisagens e o descobrimento de novas cidades através de viagens de curta ou longa distância) (MARCELLINO, 2002; SILVA; SAMPAIO, 2011). Sendo as cinco primeiras propostas por Dumazedier (1980) e a última por Camargo (2003).

Embora outro interesse seja sugerido como motivador à vivência do lazer o virtual (SCHWARTZ, 2003) - entendemos que ainda há controvérsias a respeito disso, haja vista que todos os interesses culturais citados anteriormente (físicos, manuais, artísticos, intelectuais, sociais e turísticos) são passíveis de serem vivenciados através da televisão, computador e internet. Logo, o ambiente virtual se manifesta mais como veículo do objeto do lazer (SILVA; SAMPAIO, 2011).

Os equipamentos de lazer (espaços) são classificados em: Específicos e Não-Específicos. Esses, subdivididos em: Microequipamentos, Médio Porte e Ma- 
cro Porte. Consideram-se Específicos os equipamentos criados para o lazer, como clubes, quadras esportivas, circos, parques e outros; como equipamentos NãoEspecíficos têm-se o Shopping Center, bares, casas e outros. Em geral, os Microequipamentos envolvem apenas um dos interesses culturais do lazer, enquanto os de Médio e Macro Porte envolvem mais de um interesse cultural do lazer (MARCELLINO, 2002).

Existem várias barreiras para a prática do lazer, e faz-se necessário o seu enfrentamento. As barreiras para usufruto do lazer são de cunho: Socioeconômico (a cultura da sociedade apresenta o lazer como mercadoria, onde o sujeito tem de comprar seu lazer); De diferenças socioculturais e de gênero; De centralização dos equipamentos de lazer, tanto nas pequenas como nas grandes cidades; De meios de transporte; De idade (as crianças, os adolescentes e idosos são os mais prejudicados, pois muitos desses não possuem autonomia e nem liberdade para fazerem suas próprias escolhas); De conservação dos equipamentos (ausência de políticas públicas); De ausência de animação sociocultural; De ausência de segurança (voltamos para ausência de políticas publicas), e até mesmo de acessibilidade para os necessitados (MARCELLINO, 2002; SAMPAIO, 2008).

Dentro do lazer, podemos, ainda, obter uma divisão quanto ao nível de atuação do indivíduo, ou seja, a forma com que este pensa frente a uma atividade de lazer. O primeiro nível seria o Conformista, onde o sujeito consome o lazer, sem obter nenhuma contribuição ou reflexão. O segundo seria o nível Crítico, onde o sujeito já pensa sobre, porém, não faz nenhuma comparação com a sua realidade. E por fim, o nível Crítico-Criativo, quando o sujeito já apresenta uma reflexão e traz isso para seu dia a dia (MARCELLINO, 2002).

Sabe-se hoje que o lazer, quando praticado de maneira Crítico-Criativa, pode propiciar ao indivíduo um olhar mais cuidadoso e com a possibilidade de compreensão e melhoria do seu cotidiano (MELO, 2007). Isso demonstra a importância de incentivar a prática do lazer de forma consciente, uma vez que este representa um meio de criação e escolhas.

As oportunidades de lazer segundo o conceito de Isayama (2007) devem ser vivenciadas com equilíbrio entre a prática e o consumo, buscando superar a restrição da vivência do lazer apenas a um gênero. Dessa forma, torna-se necessária a formação da população para não vivenciarem essas oportunidades apenas numa perspectiva conformista, tendo em vista que a prática não significa realização de atividade como sinônimo de participação, assim como, nem todo consumo corresponde necessariamente à passividade (SILVA e SAMPAIO, 2011).

Na concepção de Marcellino (2003, p. 37), o lazer traz para o indivíduo a ampliação social e pessoal, através do contato face a face, na melhoria e/ou aperfeiçoamento da sensibilidade. E na diversidade de conhecimentos que a prática do lazer enseja, este pode ainda "constituir-se numa denúncia da realidade, à medida que contribui para mostrar, em forma de sentimento, a contradição entre obrigação e prazer", que se faz tão presente em nosso cotidiano. 
Contudo, Pinto (2001) aborda que a educação para o lazer requer competências imprescindíveis, como: o comprometimento com os valores inspiradores da sociedade democrática; a compreensão do papel social da educação para o lazer; o domínio dos conteúdos a serem socializados, de seus significados em diferentes contextos e articulações interdisciplinares; o domínio do conhecimento pedagógico; o conhecimento de processos de investigação que possibilitem o aperfeiçoamento da prática pedagógica; e o gerenciamento do próprio desenvolvimento de ações educativas lúdicas.

Dessa forma, faz-se necessária uma intervenção profissional que considere a educação e conscientização da população, o lazer e o estilo de vida como relevantes extensões a serem tratadas, haja vista que estas extensões desenvolvem a convivência, a incorporação de valores e os hábitos saudáveis (BURGOS et al., 2009).

De acordo com Rolim (1989), o lazer propõe ao seu praticante novas pistas, fazendo com que o mesmo usufrua em sua vida da satisfação e da alegria que os valores podem proporcionar, anulando os pseudo-valores que a sociedade impõe. Com tamanha transformação e o rápido surgimento de novos valores, o lazer destaca-se como algo novo (que proporciona descanso, divertimento e o desenvolvimento do praticante).

Portanto, o objetivo do presente trabalho foi investigar a vivência do lazer na vida de futuros professores de Educação Física. O estudo tem, ainda, como objetivos específicos: avaliar as preferências de atividades de lazer dos estudantes de Educação Física; verificar os interesses culturais de lazer mais praticados por eles; verificar quais os equipamentos de lazer são utilizados, bem como quais as barreiras encontradas pelos estudantes de Educação Física para utilização destes equipamentos.

\section{Materiais e Métodos}

Este se trata de um estudo transversal, descritivo e exploratório, em que foram avaliados 175 acadêmicos do curso de Licenciatura em Educação Física de uma Instituição de Ensino Superior do Distrito Federal, sendo 72 mulheres e 103 homens, com média de idade de 23,3 anos ( $\pm 5,4$ anos), matriculados no turno matutino $(65,1 \%)$ e noturno $(34,9 \%)$. Para a inclusão dos sujeitos na amostra foram adotados os seguintes critérios: a) Ser acadêmico do curso de licenciatura em Educação Física de uma Instituição de Ensino Superior do Distrito Federal; b) Estar regularmente matriculado no semestre 2012/1; Entregar o Termo de Consentimento Livre Esclarecido assinado.

No que tange aos aspectos éticos da pesquisa, as recomendações do Conselho Nacional de Saúde - CNS/196/96 foram atendidas através da obtenção do aceite e consentimento dos acadêmicos em participar da investigação, por meio da assinatura do Termo de Consentimento Livre e Esclarecido. Ainda, o estudo 
obteve autorização do Comitê de Ética em Pesquisa da Universidade Católica de Brasília - UCB sob o número de protocolo UCB-017/2011.

Adotou-se como técnica de investigação a aplicação de dois questionários, sendo obtidas as informações relatadas de próprio punho pelos participantes da investigação.

O primeiro instrumento foi um questionário criado por Silva, Sousa e Sampaio (2012) com objetivos de avaliar o acesso e fatores impeditivos em espaços de lazer. Utilizou-se, ainda, um segundo questionário como instrumento complementar.

O primeiro questionário era composto por dois constructos: a) Acesso a equipamentos públicos específicos de lazer; b) Fatores impeditivos ao acesso a equipamentos públicos específicos de lazer. A primeira parte foi composta por 10 itens, politômicos, estruturados em escala Likert de três níveis (Nunca, Às vezes e Com Frequência). A segunda parte era composta por 12 questões fechadas, nas quais o acadêmico deveria assinalar os fatores que impedem o acesso aos equipamentos públicos específicos do lazer.

O segundo instrumento utilizado foi um questionário com questões estruturadas em escala Likert de três níveis (Nunca, Às vezes e Com Frequência), e também questões abertas. Este foi adotado para maiores esclarecimentos referentes à realização de outras atividades de lazer.

Utilizou-se uma análise estatística descritiva. Os resultados estão expressos por frequência relativa (\%). Todos os procedimentos foram realizados utilizandose do pacote estatístico SPSS 20.0 for Windows.

\section{Resultados e Discussão}

Para a descrição dos resultados, optou-se pela apresentação em tabelas.

$\mathrm{Na}$ questão 01 perguntamos aos estudantes se estes consideravam lazer e recreação como a mesma atividade: $78,7 \%$ dos estudantes responderam que não e $21,3 \%$ responderam que sim. A maioria dos estudantes justifica essa diferença dizendo que lazer é uma atividade livre, realizada no tempo livre do sujeito e a recreação acontece com e/ou sob uma orientação profissional. De fato, conceitua-se lazer e recreação de forma diferenciada, compreendendo o lazer como uma atividade mais ampla que a recreação, podendo incluí-la enquanto possibilidade de vivência de atividades geralmente associadas ao divertimento.

Nota-se, por meio das respostas obtidas, que os alunos possuem conhecimento restrito sobre o lazer, ou apresentam certo desconforto para explicar a temática abordada. Dessa forma, Silva e Silva (2012, p. 277) retratam em seu estudo, que há

[...] uma necessidade dos cursos de formação profissional em Educação Física em se ter uma produção teórica que parta do 
conhecimento dos estudantes e que faça uma mediação de significados de modo a ampliar a compreensão que tais sujeitos possuem da realidade de vida.

Para as autoras, ficou claro na fala de seus entrevistados a importância de aulas teóricas e práticas relacionadas, e, ainda, aulas que façam a relação do lazer com os demais domínios do cotidiano. Fato que para nós também se mostra importante, haja vista que muitos dos alunos não conseguiram relacionar certas atividades do cotidiano como práticas de lazer.

Os resultados indicam que os estudantes de Licenciatura em Educação Física dedicam-se com frequência às atividades de lazer, principalmente nos finais de semana $(88,7 \%)$. Dentre as atividades mais realizadas, observou-se o uso do computador $(93,1 \%)$ e assistir filmes $(57,1 \%)$, sendo o principal motivo para o uso do computador, as redes sociais, seguidas de checagem de e-mails. Por outro lado, ficou evidenciado que a maioria dos acadêmicos avaliados nunca havia realizado atividades de lazer de interesse artístico $(77,6 \%)$ e interesse manual $(74,1 \%)$.

Para a prática de atividade física como lazer é dedicada, em média, uma hora e vinte e seis minutos ( $\mathrm{DP} \pm 42,5$ minutos), sendo as atividades mais citadas: jogos de basquete, futebol, corrida e musculação. No aspecto relativo ao interesse artístico do lazer, assistir filmes foi a prática mais apontada pelos estudantes, sendo este mais praticado em casa $(95,3 \%)$. Na classificação "Às vezes", aparece que os estudantes visitam alguma exposição artística $(66,1 \%)$ e costumam viajar $(62,9 \%)$, tendo como principal motivo "férias" $(64,8 \%)$.

Estudos recentes (QUEIROZ e SOUZA, 2009; COSTA et al., 2003) observaram que, entre estudantes universitários jovens e adultos, há maior prevalência nas atividades: de interesses artísticos, como cinema; interesses intelectuais, como leitura; e interesses físico-esportivos, como jogar futebol e praticar ginástica. Estes dados corroboram com nosso estudo, onde houve uma prevalência dos mesmos interesses culturais.

Para Falco (2007), a prática do interesse artístico do lazer, por meio do cinema, promove a ruptura com o cotidiano e, através das novas experiências adquiridas com a sensibilização pelas cenas dos filmes, o indivíduo consegue atingir um determinado equilíbrio e qualidade de vida, abrindo caminhos para o conhecimento. 
Tabela 1. Análise de frequência às respostas fechadas do questionário

\begin{tabular}{lccc}
\hline \multicolumn{1}{c}{ Perguntas fechadas } & Nunca (\%) & Às Vezes (\%) & Com Frequência (\%) \\
\hline Você dedica algum tempo ao lazer? & 0 & 45,4 & 54,6 \\
\hline Você faz alguma atividade física por lazer? & 7,9 & 44,6 & 47,4 \\
\hline Você faz alguma atividade manual? & 74,1 & 17,8 & 8 \\
\hline Você faz alguma atividade artística? & 77,6 & 16,1 & 6,3 \\
\hline Você assiste filmes? & 0 & 42,8 & 57,1 \\
\hline Você assiste peças teatrais? & 38,6 & 57,4 & 3,9 \\
\hline Você assiste shows musicais? & 16,7 & 56,9 & 26,4 \\
\hline Você costuma visitar alguma exposição artística? & 30,5 & 66,1 & 3,4 \\
\hline Você faz algum tipo de leitura que não seja acadêmica? & 8 & 61,1 & 30,9 \\
\hline Você participa de alguma atividade comunitária? & 54 & 38,5 & 7,4 \\
\hline Você vai à Igreja? & 9,1 & 48,5 & 42,3 \\
\hline Você vai à casa de parentes? & 1,1 & 53,7 & 45,2 \\
\hline Você vai à casa de amigos? & 2,9 & 50,9 & 46,3 \\
\hline Você vai à festas do seu bairro? & 29,1 & 59,4 & 11,4 \\
\hline Você vai à reuniões sociais? & 20,6 & 58,3 & 21,1 \\
\hline Você costuma viajar? & 4,6 & 62,9 & 32,6 \\
\hline Você usa computador? & 0 & 6,8 & 93,1 \\
\hline
\end{tabular}

$\mathrm{Na}$ análise do uso que os acadêmicos fazem de espaços criados especificamente para a vivência do lazer, conforme pode ser observado na Tabela 2, os espaços de interesse físico-esportivo foram os que obtiveram o maior percentual de indivíduos que os utilizam com frequência - ginásio/quadra de esportes e parque/praça de esportes. Por outro lado, os equipamentos de interesses artísticos - concha acústica $(70,1 \%)$, memorial de cultura $(63,5 \%)$, teatro $(44 \%)$ e museu $(53,9 \%)$ - foram os que apresentaram o maior percentual de acadêmicos que nunca visitaram.

Tabela 2. Análise de frequência do acesso de estudantes do Curso de Licenciatura em Educação Física aos equipamentos de lazer

\begin{tabular}{lccc}
\hline Equipamentos/ Frequência & Nunca (\%) & As Vezes (\%) & Com Frequência (\%) \\
\hline Concha Acústica & 70,1 & 28,8 & 1,2 \\
Memorial & 63,5 & 35,9 & 0,6 \\
Teatro & 44 & 50,6 & 5,4 \\
\hline Biblioteca & 17,4 & 58 & 24,6 \\
Cinema & 10,8 & 50,3 & 38,9 \\
Museu & 53,9 & 43,1 & 3 \\
Praça & 19,9 & 55,4 & 24,7 \\
Parque/Praça de Esporte & 8,3 & 44 & 47,7 \\
Estádio/Campo de Futebol & 32,9 & 43,1 & 24 \\
Ginásio/Quadra de Esporte & 8,3 & 31,5 & 60,1 \\
\hline
\end{tabular}

A predominância dos espaços de interesses artísticos como aqueles com menor uso por parte dos acadêmicos de Educação Física pode estar relacionada à construção cultural existente a respeito destes espaços, pois, de acordo com Mar- 
cellino (2008), por vezes eles são revestidos com "ar de santuário", localizados no centro das cidades, se fazendo de acesso a poucos, sendo assim, conforme expõe Silva e Sampaio (2011) de acesso a poucos.

No que se refere às barreiras de utilização dos equipamentos, as opções "Nunca" ou "Às vezes" aparecem motivadas por: localização (Concha Acústica $52,4 \%$ ); falta de tempo (Teatro - 31,5\%; Estádio - 25\%) e falta de interesse (Memorial - 53,9\%; Museu - 37,5\%).

Tabela 3. Análise de frequência das barreiras de utilização dos equipamentos de lazer pe-

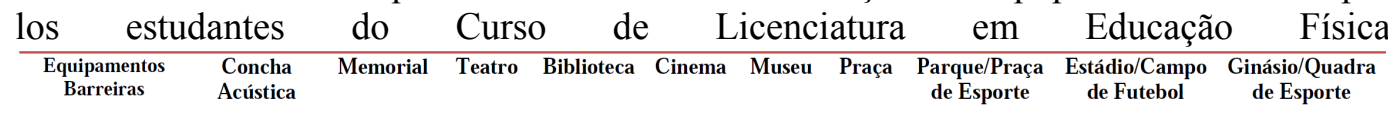

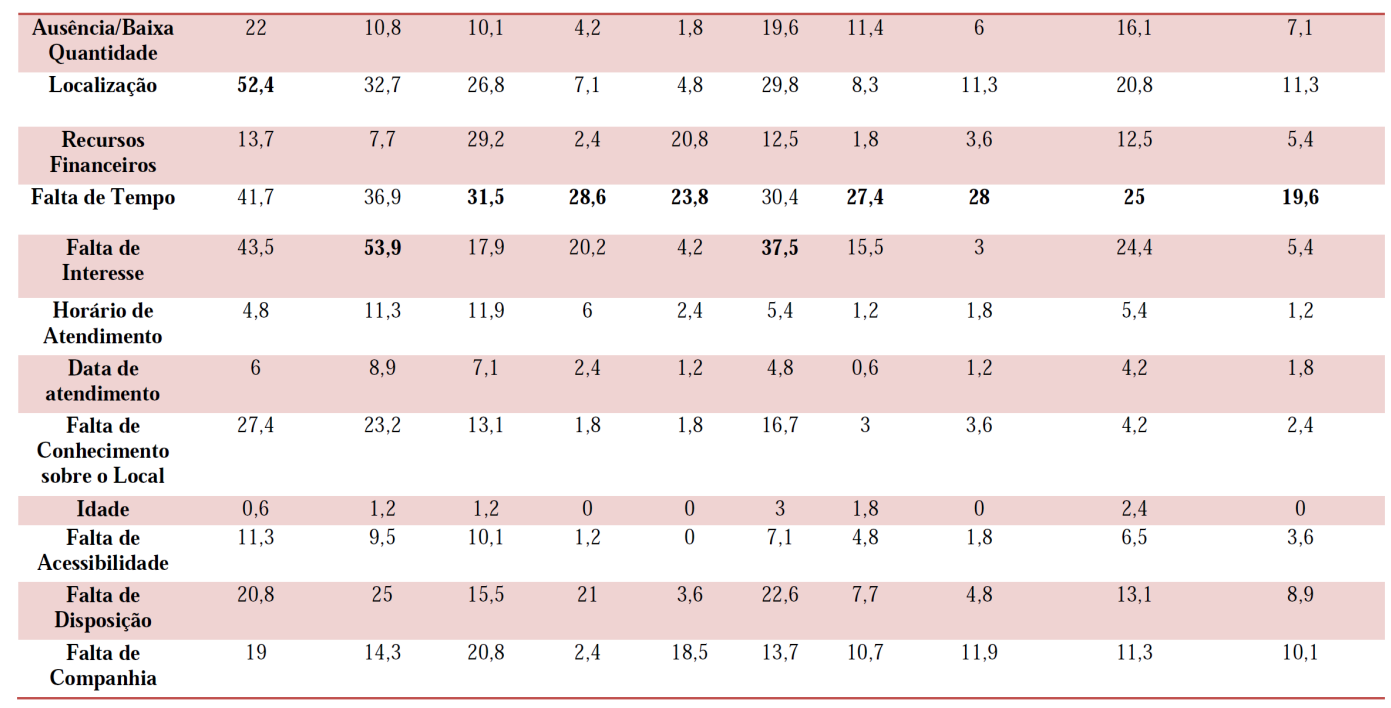

Pesquisas realizadas por Sousa e Melo (2009) identificaram algumas barreiras à opção pela visitação de museus como atividade de lazer. São estas: falta de interesse, falta de tempo, falta de entendimento e custo. Em nosso estudo, essas barreiras apareceram não somente para o museu, como também para outras atividades de cunho artístico. A essência da visita ao museu é a educação, o aprendizado. Destarte, o lazer está contemplado na definição de tal espaço, ressaltando que nesse ambiente é possível gerar a educação pelo lazer.

A barreira "Localização" apresentou número significativo para a "Concha Acústica" (52,4\%), fato que pode ser justificado pela atual concentração dos equipamentos de lazer em grandes centros e também em grandes municípios, dificultando, assim, a utilização pelos moradores das pequenas cidades e/ou regiões mais afastadas (MARIANO e MARCELLINO, 2008).

Nota-se na Tabela 3, que a barreira "Falta de Tempo" esteve presente em sete de dez barreiras, motivo este que pode ser explicado pelo fato de os estudan- 
tes trabalharem $(69,2 \%)$ e estudarem durante o curso. Acreditamos que estes estudantes, em sua maioria, trabalham para pagar as mensalidades do curso.

Isso vai de acordo com o estudo realizado por Sousa et al. (2010) com universitários da Bahia, que apresenta que, tanto praticantes como não praticantes de atividades físicas por lazer, relataram como fator limitador terem que administrar carga de trabalho com estudos. Os autores relatam, ainda, que este fato ocorre devido a uma maior preocupação com a inserção no mercado de trabalho e pelas atividades exigidas pelo próprio curso. Isso também foi observado por Reichert et al. (2007), considerando a falta de tempo como uma das principais barreiras para a prática de atividade física, e apontando a rotina de estudos e as horas dedicadas a projetos dentro da Universidade como fatores limitadores de tempo.

Analisando os resultados, nota-se a importância de se refletir sobre o lazer do jovem adulto apontando para a necessidade de contextualizar as esferas dessa manifestação ante as diferentes obrigações do ser humano. É preciso integrar o lazer com as dimensões da família, da religião, da política e, principalmente, do trabalho, uma vez que este é um dos compromissos mais presentes na vida de uma pessoa. Ainda assim, o trabalho não deveria se opor ao lazer. Faz-se necessário usufruir dos dois campos, mantendo, assim, uma relação de complementaridade (ALVES e MARCELLINO, 2010).

Reed e Phillips (2005) apresentam um provável fator influenciável à prática de atividades físicas de estudantes universitários: a proximidade e facilidade de acesso a locais para esta prática. Sendo assim, a própria Universidade, com seus múltiplos espaços, poderia ser também um equipamento não-específico do lazer, promovendo atividades voltadas para a vivência dos diversos interesses culturais.

Contudo, as possibilidades de experiência do componente lúdico da cultura na vida adulta são limitadas. Nesse sentido, Alves e Marcellino (2010) expõem que o jogo, por exemplo, surge como uma das possibilidades de "libertação", e o profissional de Educação Física, no papel de animador sociocultural, pode contribuir para o desenvolvimento do pensar Crítico-Criativo, além de propiciar o exercício para a cidadania. Isso porquê, por meio do divertimento e do desenvolvimento pessoal, o lazer proporciona a transformação do indivíduo em pessoa, e no que tange ao desenvolvimento social, a transformação da pessoa em cidadão, e ainda recupera o lúdico na vida do adulto.

Fica claro, portanto, que o educador tem como papel o compromisso e a consciência histórica de se perceber enquanto sujeito transformador da realidade. E no campo do lazer, o mesmo deve proporcionar a construção do conhecimento baseado na perspectiva coletiva e na participação comunitária (FIGUEIREDO et al., 2010a).

As atividades de lazer são vistas como uma importante prática educativa, pois possibilitam o fortalecimento e a organização social de determinados grupos e ainda visam à emancipação do ser humano. Sendo assim, faz-se necessária uma "educação para além do capital" que possibilite uma formação reflexiva e crítica, 
e que possibilite ao educando e ao educador modificar as condições de alienação e de subversão fetichista nas quais estão inseridos, mostrando, assim, a importância da formação do profissional de Educação Física e de outras áreas aptas para atuarem com o lazer (FIGUEIREDO e ALMEIDA, 2010b).

Confirmando a ideia exposta acima, Seabra et al. (2004) revela que a família, amigos e os professores de Educação Física são os principais influenciadores das escolhas de estudantes em idade escolar. Por meio deste fato, devemos compreender melhor a ligação entre lazer e Educação Física. O profissional desta área deve ser o "mediador na questão do conhecimento e escolha das atividades, orientando como se utilizam determinados espaços e equipamentos de lazer" (SILVA e SILVA, 2012, p. 273).

No entanto, Marcellino (2003) relata que as manifestações do lazer e da educação ultrapassam os conteúdos culturais citados (manual, artístico, intelectual, social, físico-esportivo, turístico e virtual), evidenciando estas manifestações como características de uma participação cultural, como falado anteriormente, um momento de criação.

\title{
Considerações Finais
}

Com base nos resultados, observamos que os estudantes do curso de Licenciatura em Educação Física preferem atividades de lazer como: "Assistir a Filmes" e "Usar o computador". Eles possuem pouca experiência com equipamentos de lazer, e a sua maior utilização está concentrada em dois deles: ginásios/quadra de esportes e parques/praças esportivas. Nota-se que as principais barreiras para utilização dos equipamentos são a falta de tempo, a falta de interesse e a localização dos equipamentos. Os principais interesses culturais desses estudantes são os artísticos e os físicos-esportivos. Ressaltamos que o lazer apresenta um importante papel para a educação, por meio da atuação Crítico-Criativa.

Desta forma, deve haver uma melhor formação para esses profissionais e que contemple o leque do lazer. Fazem-se necessárias aulas com uma conexão de teoria e prática, bem como com ligação entre lazer e cotidiano.

\section{LEISURE EXPERIENCE OF STUDENTS OF COURSE BACHELOR OF PHYSICAL EDUCATION OF AN INSTITUTION OF HIGHER EDUCATION FEDERAL DISTRICT}

\begin{abstract}
Leisure can be understood by two constituent aspects, attitude and time. Therefore, the objective of this study was to investigate the understanding and experience of leisure in the lives of future professionals in the field of Physical Education. The sample consisted of 175 students of Bachelor of Physical Education of an Institution of Higher Education of the Federal District. The results indicate that students of Bachelor in Physical
\end{abstract}


Education devote some leisure time. It can be concluded that students of the Bachelor's Degree in Physical Education have little experience with leisure facilities. The main barriers to the use of equipment are lack of time, lack of interest and location of equipment.

Keywords: Leisure. Cultural Interests. Equipment.

OCIO EXPERIENCIA DE ESTUDIANTES DE BACHILLERATO EN CURSO DE EDUCACIÓN FÍSICA DE UNA INSTITUCIÓN DE EDUCACIÓN SUPERIOR DEL DISTRITO FEDERAL

\section{Resumen}

Ocio puede ser comprendido por dos aspectos constitutivos, la actitud y el tiempo. Por lo tanto, el objetivo de este estudio fue investigar el conocimiento y la experiencia de ocio en la vida de los futuros profesionales en el campo de la Educación Física. La muestra estuvo constituida por 175 estudiantes de la Licenciatura en Educación Física de una Institución de Educación Superior del Distrito Federal. Los resultados indican que los estudiantes de la Licenciatura en Educación Física dedicar un poco de tiempo libre. Se puede concluir que los estudiantes de la Licenciatura en Educación Física tienen poca experiencia con instalaciones de ocio. Las principales barreras para el uso de equipo son la falta de tiempo, falta de interés y la ubicación de los equipos.

Palabras clave: Ocio. Actividades Culturales. Equipo.

\section{Referências}

ALVES, Cathia; MARCELLINO, Nelson Carvalho. Adulto e lúdico: atuação do profissional de Educação Física no lazer. Motriz, Rio Claro, v.16, n.1, p. 103-112, jan./mar. 2010.

BURGOS, Miria Suzana; GAYA, Adroaldo Cezar; MALFATTI, Carlos Ricardo Maneck; MULLER, Ademir; BURGOS, Leandro Tibiriçá; POHL, Hildegard Hewwing; REUTER, Cézane Priscila. Estilo de vida: lazer e atividades lúdicodesportivas de escolares de Santa Cruz do Sul. Rev Bras. Educ. Fis. Esporte, São Paulo, v.23, n.1, p. 77-86, jan/mar. 2009.

CAMARGO, Luís Otávio de Lima. O que é lazer. São Paulo: Brasiliense, 2003.

COSTA, Rosana Salles; HEILBORN, Maria Luiza; WENERCK, Guilherme Loureiro; FAERSTEIN, Eduardo; LOPES, Claudia S. Gênero e prática de atividade física de lazer. Caderno de saúde pública, Rio de Janeiro, 2003.

DUMAZEDIER, J. Valores e Conteúdos culturais do lazer. São Paulo: SESC, 1980. 
FALCO, Débora de Paula. Lazer fora de casa: o cinema como equipamento mágico do urbano. Licere, Belo Horizonte, v.10, n.1, abr/ 2007.

FIGUEIREDO, Pedro Osmar Flores de N.; ALMEIDA, Dulce Figueira. Educação e Formação dos Trabalhadores do Programa Esporte e Lazer da Cidade. In: ALMEIDA, Dulce Figueira. Política, Lazer e Formação. 2010b

FIGUEIREDO, Pedro Osmar Flores de N.; SAMPAIO, Juarez Oliveira; BEHMOIRAS, Daniel Cantanhede; DALMAS, Leandro Casarin; COSTA, Júlio Cesar Cabral. Uma Proposta Didático - Metodológica do Coletivo de Formação. In: ALMEIDA, Dulce Figueira. Política, Lazer e Formação. 2010 .

GIL, A. C. Métodos e técnicas de pesquisa social. $6^{\text {a }}$. ed. São Paulo: Atlas, 2010.

ISAYAMA, Helder F. Reflexões sobre conteúdos físicos-esportivos e as vivências do lazer. In: MARCELLINO, Nelson Carvalho. Lazer e Cultura. Campinas: Alínea, 2007.

MARCELLINO, N. C. Lazer e sociedade: Algumas aproximações. In: MARCELLINO, N. C.(Org.). Lazer e Sociedade: múltiplas relações. Campinas, SP: Alínea, 2008. Cap. 1. P. 11-26.

MARCELLINO, Nelson Carvalho. Estudos do Lazer, uma introdução. Campinas, SP: Autores Associados, 2002.

MARCELlinO, Nelson Carvalho. Pedagogia da Animação. Campinas, SP: Pa-

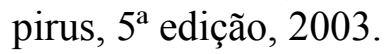

MARIANO, Stéphanie Helena; MARCELLINO, Nelson Carvalho. Equipamentos de lazer em cidades pequenas da região metropolitana. Motriz, Rio Claro, v. 14, n.2, p. 168-178, abr.jun., 2008.

MELO, Victor Andrade. Arte e Lazer: Desafios para Romper o Abismo. In: MARCELLINO, Nelson Carvalho (organizador). Lazer e Cultura. Editora Alínea, Campinas, SP. 2007, p. $31-46$.

PINTO, Leila Mirtes Santos de Magalhães. Formação de educadores e educadoras para o Lazer: Saberes e Competências. Rev. Bras. Cienc. Esporte, v. 22, n. 3, p. 53-71, maio 2001. 
QUEIROZ, Marine Nogueira Gonçalves; SOUZA, Luciana Karine. Atividades de lazer em Jovens e Adultos: Um estudo descritivo. Licere, Belo Horizonte, v.12, n.3, set/2009.

REED, J. A., PHILLIPS, D.A. Relationships between physical activity and the proximity of exercise facilities and home exercise equipment used by undergraduate university students. J Am Coll Health, 2005; 53(6): 285-90.

REICHERT, F. F., BARROS, A. J. D., DOMINGUES, M. R., HALLAL, P. C. The role of perceived personal barriers to engagement in leisure-time physical activity. American Journal Public Health, 2007; Mar; 97(3): 515-9.

ROLIM, Liz Cintra. Educação e Lazer: A Aprendizagem Permanente. São Paulo: Editora Ática, 1989.

SAMPAIO, Tânia Mara Vieira. Gênero e Lazer: um binômio instigante. In N. C. MARCELLINO (Ed.), Lazer e Sociedade, múltiplas relações, p. 139-154, Campinas, SP: Alínea, 2008.

SAMPAIO, Tânia Mara. Conhecimento científico: capacidade humana de intervir reinventando e revertendo a sina Severina. In: MOREIRA, Wagner W. e SIMÕES, Regina (orgs.). Educação Física: intervenção e conhecimento científico. Piracicaba: UNIMEP, 2004.

SCHWARTZ, Gisele M. O conteúdo virtual do lazer: contemporizando Dumazedier. Revista Licere, v. 2, n.1. Belo Horizonte, UFMG, 2003.

SEABRA, André Filipe Teixeira; MENDONÇA, Denisa Maria de Melo Vasques; GARGANTA, Rui Manoel; MAIA, José Antônio Ribeiro. Influência de determinantes demográficos-biológicos e sócio-culturais nos níveis de atividade física de crianças e jovens. Rev Bras Cine Des Hum, v.6, n.2, p.62-72, 2004.

SILVA, J. V. P.; SAMPAIO, T. M. O lazer e suas diversas faces. In: SAMPAIO, T. M. V.; SILVA, J. V. P. Lazer e cidadania: horizontes de uma construção coletiva. Brasília: Universa, 2011. p. 45-66.

SILVA, Junior Vagner Pereira; SOUSA, Ioranny Raquel Castro; SAMPAIO, Tânia Mara Vieira. Acesso de Meninas e Meninos de Ceilândia DF a Espaços Específicos de Lazer. In: Seminário O Lazer em Debate, 2012, Belo Horizonte. O lazer em debate. Belo Horizonte: UFMG/DEF/CELAR, 2012. v. XIII. p. 120-125. 
SILVA, Tatyane Perna; SILVA, Cinthia Lopes da. Educação Física e Formação Profissional para o Lazer. In: ISAYAMA, H. F.; OLIVEIRA, M. A. T.; CASTILHO, C. T.; OLIVEIRA, K. B. Coletânea do XII Seminário "O lazer em Debate" - Belo Horizonte: UFMG/DEF/CELAR, 2012.

SOUSA, Cleide Aparecida Gonçalves; MELO, Victor Andrade. Museu, Emoção estética e Lazer: Reflexões sobre as possibilidades da fruição da arte no tempo livre. Licere, Belo Horizonte, v.12, n.1, abril, 2009.

SOUSA, Thiago Ferreira; SANTOS, Sueyla Ferreira da Silva dos; JOSÉ, Helma Pio Mororó. Barreiras percebidas à prática de atividade física no Nordeste do Brasil. Pensar a Prática, Goiânia, v.13, n.1, p. 1-15, jan./abr. 2010.

Recebido em: 10/10/2012

Revisado em: 16/04/2013

Aprovado em: 06/05/2013

Endereço para correspondência:

Ioranny Raquel Sousa

iorranyraquel@gmail.com

Universidade Católica de Brasília

Campus Avançado Asa Norte - SGAN 916

Módulo B Avenida W5

CEP: 70790-160 - Brasília/DF 